\title{
Preliminary results of a district call scheme for cervical screening organised in general practice
}

\author{
Christine M Havelock, Janet Webb, Jeremy Queenborough
}

\begin{abstract}
A recognised problem with the cervical screening programme in the United Kingdom is the failure to include women who have never had a cervical smear test, who are a high risk group. The implementation of a district based call scheme in East Berkshire in 1986 is described whereby women aged 20-64 with no record of a cervical smear test who were judged to be eligible for testing by their general practitioner were sent a personal invitation from their general practitioner to attend for a test. A list of high risk unscreened women was kept by each practice, and a duplicate sent to the cytology laboratory to update the central records. Six months after each batch of invitations had been sent the resulting number of women having a smear test was assessed. Forty three of 51 practices approached agreed to participate in the five year scheme. During the first year lists were sent to the 43 participating practices. The first list was returned to the cytology laboratory by 37 practices and the second by 33 ; practices varied in their responses, however, some needing considerable persuasion to return the lists. Of 972 identified unscreened women from the total 3757 women listed in the lists of the family practitioner committee, 247 $(25 \%)$ had a cervical smear test in response to the invitation, representing an overall increase of $7 \%$ in the screened population.

The preliminary findings of the five year study have shown that screening can be improved by a systematic call scheme. Coordinated support from the area health authority in health education, monitoring of screening, and feedback of data from the scheme to practices is required to reduce the proportion of unscreened women.
\end{abstract}

\section{Introduction}

The results of the past 20 years of cervical screening in the United Kingdom have been disappointing, largely owing to the failure to screen middle aged and older women who are most at risk from developing cervical cancer. ${ }^{1}$ This unscreened high risk group is not caught by opportunistic or spontaneous screening. ${ }^{2}$ Organised or systematic screening programmes are, however, much more successful in increasing coverage of the population and reducing incidence of invasive cervical cancer and associated mortality. ${ }^{3}$

In the United Kingdom general practice is the obvious setting for cervical screening. ${ }^{+}$The general practitioner is ideally placed to offer reassurance about the disease and the test, particularly to women in the older age groups, whose opportunities for screening are diminished as they no longer attend antenatal, postnatal, or family planning clinics. Encouragement and persistence from general practice can lead to high numbers of these women accepting the offer of a smear test. $^{47}$ General practitioners are, however, not a uniform group, and, though many have efficient and effective systems, not all will perform enthusiastically and effectively in a cervical screening programme. We have described several barriers that prohibit general practitioners from taking smears and from performing organised cervical screening within their practices. ${ }^{8}$

We established a computerised call and recall scheme in East Berkshire in October 1986 and have attempted to maximise the skills and resources in general practice by identifying and overcoming the barriers to screening. The objectives of the district cytology scheme are $(a)$ that all. women aged 35-64 (now extended to 20-64) for whom there is no record of a cervical smear test who are eligible for screening should be invited to attend for a test and $(b)$ that all women should be retested at intervals of no more than five years.

We report on the implementation of the first objective during the first year of the call scheme.

\section{Methods}

CALL SCHEME

A preliminary protocol for the scheme was presented to the district health authority in January 1985. A steering group convened with representation from all disciplines with clinical or administrative interest in cervical screening agreed that in the initial stages priority should be given to screening women for whom no record of cervical screening was held who resided in the health district.

The principal features of the scheme are that the overall management is by the district health authority; the scheme focuses on general practice, with general practitioners being responsible for sending invitations and arranging for testing; the women are identified by the cytology laboratory, which provides day to day coordination with emphasis on developing personal contact between the organisers of the scheme and the primary health care teams; sufficient staff are employed to run the scheme, in this case comprising one and a half higher clerical officer grade posts based in the laboratory, one clerical post in the family practitioner committee, and one and a half cytology screening posts; and accurate information is collected about practices, their facilities, and the established method of cervical screening, if any.

\section{IDENTIFICATION OF UNSCREENED WOMEN}

When the scheme was implemented the Berkshire Family Practitioner Committee was not computerised. We asked all general practitioners for permission for access to their records and compiled a register of women arranged by their date of birth and general practitioner by transcribing the records of women in the selected age groups held by the family practitioner committee on to a minicomputer in the department of community medicine. The register is updated with information received from the family practitioner committee about population movements. 
By comparing the entries in the register with those in the cytology records from the laboratory we have identified women who had no record of a cervical smear and have listed them for each general practitioner. To control the workload for both staff taking the smears and those in the laboratory the women are identified in batches every three months over five years. Each batch consists of women in the first three months of their 36th, 41st, 46th, 51st, 56th, and 61st years.

\section{IMPLEMENTATION OF SCHEME}

As the scheme focuses on general practice the full commitment of general practitioners is imperative. Meetings to explain the district objectives for cervical screening and to receive suggestions about the implementation of the scheme have been arranged between the organisers and the general practitioners and their primary health care teams and were held in the general practitioners' surgeries. Among the points discussed were the evidence for the effectiveness of cervical screening when organised and properly implemented; the effectiveness of general practitioners in persuading previously reluctant women to attend for testing; the value of consultation to deal with women's fears and anxieties about cervical cancer and screening; possible solutions for problems anticipated within the practices, particularly those related to time, space, and staffing; the wording of the invitation and the importance of flexibility in arranging appointments; the importance of actively informing the women of the results of their tests and giving guidance on the time of the next test; and the provision of feedback by the laboratory to each general practitioner on his or her efficiency and effectiveness.

All practices were asked to nominate a person to be responsible within the practice for organising the scheme and providing the point of contact between the district organisers and the practice. It was suggested that this person should have a special interest in cervical screening and could be a doctor, nurse, receptionist or clerk.

Each practice is sent comprehensive written instructions about the scheme and two copies of their list of registered women for validation and action. One is kept in the practice as a working copy and the other returned to the laboratory so that the central records may be amended. When a list is returned the next is sent. The tasks in the practice are to confirm the identity of the women from the practice records; to check if and when a cervical smear test has been carried out, other than that recorded on the cytology computer; to assess the woman's eligibility for routine screening from the history, with particular reference to sexual activity, hysterectomy, and other conditions that in the general practitioner's opinion preclude screening; and to invite women for testing with a definite appointment. Practices failing to return the lists to the laboratory are reminded of this at regular intervals and, if necessary, contacted by the community physician to see if they needed help or advice.

Six months are allowed for the women to respond to the invitation. The cytology records are then checked against the lists of unscreened women to assess how many women have been tested as a result of the call.

All the results are sent to the practices so that each can compare its progress with the others; the practices are coded to preserve anonymity.

The results obtained from the first year of the scheme are presented.

\section{Results}

Participation by general practitioners-Representatives from 38 of the 51 practices in the district $(75 \%)$ attended the meetings to discuss the scheme. Practices in the most densely populated areas were the least well represented whereas attendance was high from practices in rural and semirural areas. Seven practices were confident that their own screening system was effective, and they consequently declined to take part in the scheme. Only one practice did not give permission for their records to be used to compile the register.

Return of lists by general practitioners - Table I shows the return of lists to the cytology laboratories by participating practices. The first list was returned by

TABLE I-Return of lists by general practitioners participating in call scheme

\begin{tabular}{|c|c|c|}
\hline & First list & Second list \\
\hline No of lists returned & 37 & 33 \\
\hline Spontaneously & 13 & 20 \\
\hline After persuasion & 24 & 13 \\
\hline No of lists not returned & 6 & 8 \\
\hline Delay in issue of list & & 2 \\
\hline
\end{tabular}

37 practices, although not all practices responded with the same degree of enthusiasm and efficiency; 13 responded spontaneously, but the remaining 24 required considerable reminding and persuasion. Six practices $(12 \%)$ failed to return the list. After the second list had been issued the number of spontaneous returns increased to $20 ; 10$ practices needed reminders, but only three needed more persistent persuasion. Eight practices failed to return the list, the original six plus two more. The issue of the second list to two practices was delayed because of a computer failure in the district. At follow up all the practices that had not returned the lists were found to have particular problems. Two male doctors in one practice do not take cervical smears and have no intention of ever doing so, and the senior partner of another practice does not believe in the effectiveness of cervical screening and takes smears only on request. Six practices are single handed practices in urban settings with male practitioners whose patients are mostly Asian - that is, people from the Indian subcontinent - who considered that without a female partner or nurse it was not acceptable to take cervical smears from the Asian women.

Identification of unscreened women-Table II shows the information collected from the first and second lists. Of 3757 women in the 20-64 age group, 2972 were

TABLE II-Identification of unscreened women eligible for cervical smear testing

\begin{tabular}{lr}
\hline & No \\
\hline Total & 3757 \\
Not identified in the practice & 395 \\
Not eligible for screening & 390 \\
With previous smear test & 2000 \\
Unscreened & 972
\end{tabular}

eligible for testing, 390 were excluded for clinical reasons, and 395 could not be identified in the practice registers. A smear test result was found for 2000 women. No record of a smear test could be found, either in the laboratory records or the practice records, for 972 of the original 3757 women.

Update of smear testing - After six months the laboratory records were checked; Table III shows the findings. Test results were found for $247(25 \%)$ of the 972 previously untested women, leading to an overall increase in the screened population of $7 \%$. The response in the women over 50 was $24 \%(130 / 531)$ compared with that of $27 \%(117 / 441)$ in those under 50. 
TABLE III-Uptake of cervical smear screening in response to invitation by age

\begin{tabular}{lcccccccc}
\hline & \multicolumn{8}{c}{ Age (years) } \\
\cline { 2 - 7 } & 36 & 41 & 46 & 51 & 56 & 61 & \multirow{2}{*}{ Total } \\
\hline No unscreened & 152 & 156 & 133 & 146 & 187 & 198 & 972 \\
No $(\%)$ receiving smear & $41(27)$ & $41(26)$ & $35(26)$ & $32(22)$ & $46(25)$ & $52(26)$ & $247(25)$ \\
\hline
\end{tabular}

\section{Discussion}

In the first few months of the scheme we have shown that a shift from opportunistic cervical screening largely initiated by women to an organised scheme initiated by general practitioners resulted in a $25 \%$ increase in the uptake of screening in women with no history of screening.

Involvement of the general practitioners from the outset has avoided some of the problems reported in other studies. ${ }^{9}$ There is an increased awareness among general practitioners of the difficulties in achieving effective cervical screening. Many practices have responded by either reorganising their existing staff or employing more staff to cope with the extra demands. Inappropriate invitations, to women who have moved away and to those who are not eligible for testing, have been minimised.

Considerable effort is, however, required to keep the scheme running efficiently. As anticipated, general practitioners' responses have been variable. Although many welcomed the scheme and joined it enthusiastically, the response from others has been slow. About half the practices needed constant reminding and considerable persuasion to return the lists, but as the scheme has progressed and more practices have become organised the proportion of spontaneous returns has increased.

Problems with the non-participating practices persist. In practices in which the doctors have no interest in cervical screening arrangements are being made for the women to be directly invited by the family practitioner committee and facilities for testing are being made available in the local family planning clinic. All the practices with high numbers of Asian women are taking steps to employ female staff to take smears and intend to join the scheme soon.

Before setting up the scheme we had no information about the number of women screened in our district population. ${ }^{10}$ We have confirmed that a realistic target for screening is $80 \%$ of the women in the selected age group $^{11}$ and found that about two thirds of these women had already been tested. Within the remaining third are the women at particular risk from developing carcinoma of the cervix. ${ }^{12}$ Several reasons have been suggested for their non-attendance ${ }^{13}$ : ignorance of the relevance of the test ${ }^{14}$; fear of the test and of the disease $^{15}{ }^{16}$; lack of female staff to take smears ${ }^{17}$; and inconvenient locations and times for testing, ${ }^{15}$ all of which must be taken into account when inviting women for testing. ${ }^{9}$

These issues are difficult to deal with on a district basis. Personal contact with the women ${ }^{18}$ is now required with emphasis on the preventive nature and personal benefits of the test to the individual women. ${ }^{19}$ The district organised scheme with computerised listings of women in need of testing is the essential first step, the next must come from the practices. Once the unscreened women have been identified letters of invitation can be sent and practice records marked as a reminder to any member of the primary health care team to discuss cervical screening when the woman next attends the surgery.

Although we have shown the value of utilising the extensive resources already available within general practice to include unscreened women in the cervical screening programme, a considerable number of women in our study have not had a cervical smear test. The scheme is, however, in the early stages and general practitioners will perhaps be persuaded to follow up systematically the non-responding women within their practices thus ensuring that failure to be screened is founded on a woman's informed refusal of a test rather than lack of information or disinterest among the health care professionals.

Responsibility for the success or failure of cervical screening should not rest with general practice alone. The provision of lists of women who need testing to general practitioners is in itself insufficient to increase the uptake of tests by the high risk group. Much greater awareness of the problems facing general practitioners is needed, and a coordinated response from the district health authority is required to provide support for individual practices, including practical help by district facilitators within the practice, help with the non-attenders through the contacts of health visitors and district nurses, local health promotion for women, regular acceptable education for health professionals, monitoring of results of screening, and feedback on achievements in individual practices and throughout the district.

Though our results are disappointing, they show an appreciable improvement on currently available figures for cervical screening. We think that our preliminary findings indicate the coordinated approach needed if we are to achieve the decrease of mortality in cervical cancer in Scandinavian countries.

We thank Dr Peter Havelock for his insight into general practice; Dr M H Ali, head of the histology and cytology department for his support; Marjorie Hutchings for the day to day running of the project; and Colin Webb for editorial comment.

1 Intercollegiate Working Party on Cervical Cytology Screening. Report. Hertfordshire: Progress Press, 1987:6.

2 Anonymous. Cancer of the cervix: death by incompetence [Editorial]. Lances 1985 ;ii:363-4

3 Laara $E$, Day NE, Hakama $M$. Trends in mortality from cervical cancer in the Nordic countries: association with organised screening programmes. Lance $1987 ; \mathrm{i}: 1247-9$

4 Wakefield J. The family doctor and cervical cytology. In: Wakefield J, ed. Seek wisely to prevent. London: HMSO, 1972:28-37.

5 Williams PA, Williams $M$. Barriers and incentives for primary care physicians in cancer prevention and detection. Cancer 1987;60:1970-8.

6 Standing P, Mercer S. Quinquennial cervical smears: every woman's righ and every general practitioner's responsibility. Br Med f 1984;289:883-6.

7 The ICRF Coordinating Committee on Cervical Screening. The managemen of a cervical screening programme: a statement (October 1985). Community Med 1986;8:179-84

8 Havelock CM, Edwards R, Cuzick J, Chamberlain J. The organisation of cervical screening in general practice. $\mathcal{F}$ Coll Gen Pract 1988;38:207-11.

9 Elkind A, Haran D, Eardley A, Spencer B. Computer-managed cervical cytology screening: a pilot study of non-attenders. Public Health 1987;101: cytology.

10 Draper GJ. Screening for cervical cancer: revised policy. The recommendations of the DHSS Committee on Gynaecological Cytology. Health Trends 1982;14:37-40.

11 Cook GA, Draper GJ. Trends in cervical cancer and carcinoma in situ in Grea Britain. Br f Cancer 1984;50:367-75

12 Macgregor JE. Screening for pre-clinical cervical cancer. In: Jordan JA, Sharp F, Singer A, eds. Preclinical neo-plasia of the cervix. Proceedings of the nint study group of the Royal College of Obstetricians and Gynaecologists. London Royal College of Obstetricians and Gynaecologists, 1982:95-7.

13 Eardley A. Influences on women's behaviour in relation to cancer screening. In: Faculty of Economic and Social Research working papers in applied social research. Manchester: University of Manchester, 1984. (Working social research

14 King JB. "It's silly, but I just don't want to know." Health Services 1983;11 March: 13 .

15 Houghton H. Response to cervical screening. Medical Officer 1968;120:334-6.

16 Spenser JT. A survey of cervical smear testing in general practice. Practitioner 1967; 198:274-80

17 Sansom CD, Wakefield J, Pinnock K. Choice or chance? How women come to have a cytotest done by their family doctor. In: Wakefield J, ed. Seek wisely to prevent. London: HMSO, 1972: 122-8.

18 Thompson C. Cervical cytology consent rate. Lancet 1969;ii:385.

19 King JB. Health beliefs, attributions and health behaviour [PhD Thesis]. Oxford: University of Oxford, 1982

Accepted 4 October 1988 